\title{
Triple-Plane Dissection of Combined Forehead and Scalp Flaps for Large Posttraumatic Forehead Defects
}

\author{
Srinjoy Saha ${ }^{1}$ \\ 1Department of Plastic Surgery, Apollo Gleneagles Hospital, \\ Kolkata, West Bengal, India
}

Int J Recent Surg Med Sci 2020;6:24-29

\begin{abstract}
Address for correspondence Srinjoy Saha, MBBS, MS, MRCS, MCh (Plast), Department of Plastic Surgery, Apollo Gleneagles Hospital, Day Care Building 2nd Floor, 58 Canal Circular Road, Kolkata 700054, West Bengal, India (e-mail: ss@medi.ac).
\end{abstract}

\begin{abstract}
Keywords

- forehead reconstruction

- forehead anatomy

- scalp anatomy

- forehead flap

- reconstructive surgical procedures

Introduction Reconstruction of large $\left(>20 \mathrm{~cm}^{2}\right)$ posttraumatic forehead defects, with esthetically pleasing results and without distorting the surrounding anatomical landmarks like eyebrow and hairline, is a significant surgical challenge. This study was aimed to determine the effectiveness of a triple-plane dissection technique of significantly-sized flaps, combining forehead, and scalp to cover large forehead defects.

Materials and Methods A retrospective review from January 2009 to December 2019 revealed that 12 patients with large defects over the forehead were operated on. Significantly-sized rotation and advancement flaps, combining both the forehead and scalp tissues, were performed. Triple-plane dissection and careful galeal scoring recruited more tissues and increased the reach of these flaps while maintaining adequate flap vascularity.

Results Large forehead posttraumatic defects in all 12 patients were covered in a single surgery with this combined flap. Eight patients were men and four were women (mean age, 58 years). Size of the defects ranged from 21 to $40 \mathrm{~cm}^{2}$ (mean, $27 \mathrm{~cm}^{2}$ ). Complications included deep marginal necrosis in one patient ( $8 \%$ ), superficial necrosis in one patient (8\%), and mild venous stasis in four patients (33\%). Superficial necrosis and venous stasis resolved by itself. Good color and contour match, minimal alopecia, maintained positions of eyebrow, and hairline positions were found in most patients. Six months postoperatively, patient satisfaction measured on a visual analogue scale ranged between 3 and 9 out of 10 (mean, 7).

Conclusion Primary forehead reconstruction with significant-sized flaps combining forehead and scalp tissues, with triple-plane dissection and galeal scoring, appears to be an effective option for covering large forehead defects.
\end{abstract}

\section{Introduction}

Posttraumatic large forehead defects are a reconstructive dilemma. Anatomic landmarks and esthetic subunits need special attention. ${ }^{1}$ It is a challenge to match color, texture, and contour of the forehead skin while maintaining the defining anatomic landmarks, namely, eyebrows and hairline. ${ }^{2}$ Forehead defects are classified according to their size, with $<10 \mathrm{~cm}^{2}$ being small, 10 to $20 \mathrm{~cm}^{2}$ being moderate, and $>20 \mathrm{~cm}^{2}$ being large. ${ }^{3}$ According to the reconstructive ladder described by
Mathes and Nahai, defects over the forehead may be repaired by any of the following reconstructive procedures: healing by secondary intention, primary closure, skin grafting, local flaps, regional flaps, and free-tissue transfers. ${ }^{4}$

In any reconstruction, an optimal approach is to replace "like tissues with like," while being the simplest to perform. With increasing consciousness about esthetic outcomes, patients increasingly demand a normal-looking result with minimal scars. I intended to determine the effectiveness of a triple-plane dissection technique of significant-sized flaps,
DOI https://doi.org/

$10.1055 / \mathrm{s}-0040-1713686$

ISSN 2455-7420.
License terms

(ㅇ) (1) $\ominus \circledast$ 
combining forehead and scalp, to cover large forehead defects in posttraumatic adult patients. Alongside, the complications and long-term patient satisfaction rates were documented.

\section{Materials and Methods}

A retrospective review was performed for patients presenting with large $\left(>20 \mathrm{~cm}^{2}\right)$, posttraumatic, full-thickness, forehead defects, and primarily reconstructed with rotationadvancement flaps combining forehead and scalp tissues. Twelve such patients were operated on between January 2009 and December 2019 under general anesthesia. All these patients followed-up for a minimum of 6 months after the surgery. Their ages ranged between 34 to 86 years, with a mean of 58 years, and the male-to-female distribution was $8: 4$. Seven patients (58\%) presented after automobile accidents, three (25\%) after industrial workplace accidents, and two (17\%) after falling from height or stairs. The size of defects over the forehead ranged between 21 to $40 \mathrm{~cm}^{2}$, with a mean of $27 \mathrm{~cm}^{2}$. Preoperative computed tomographic scans assessed all patients for underlying brain injuries. All patients received preoperative, intraoperative, and postoperative antibiotic cover according to the preoperative culture and sensitivity results.

\section{Relevant Surgical Anatomy}

Vascular supply of the forehead and scalp was outlined before designing the flap. It was essential to note the vascular course of supratrochlear, supraorbital, superficial temporal, and occipital vessels, and mark the points where they became superficial. ${ }^{5,6}$ Frontalis attachments forming the transverse relaxed skin tension lines (RSTL)over the forehead, and the corrugators forming the midline vertical RSTL were also marked. Final scars were oriented along these lines to conceal them as much as possible.?

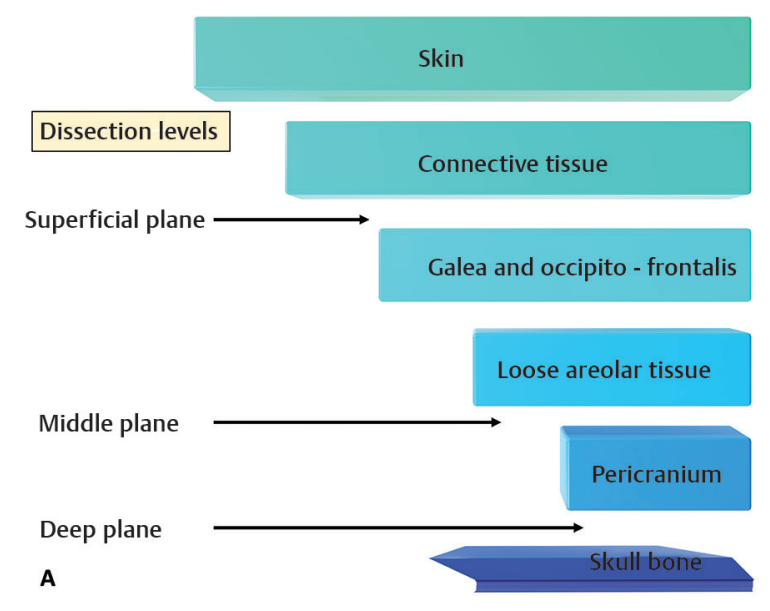

\section{Rotation-Advancement Flap Design}

Flaps were designed to beat least five to eight times larger than the original defect and were rotated and advanced simultaneously. The significant size of the flaps reduced tension over the flap margins. Resulting dog-ear at the point of rotation was corrected primarily.

\section{Triple-Plane Dissection}

Dissection was performed in three different planes during the surgery. Superficial plane dissection occurred superficial to the frontalis muscle and galea for a variable width. Middle plane dissection occurred along with the areolar space between the galea and the pericranium up to the nuchal lines posteriorly, temporal lines laterally, and above the frontal rim anteriorly. Deep plane dissection went underneath the pericranium around these above-mentioned lines and lay over the skull bones or fascia of vertebral and temporal muscles posteriorly and laterally, respectively ( - Fig. 1A). Knowledge of the anatomic points, where the underlying blood vessels became superficial, was essential during this dissection. ${ }^{8}$

\section{Scoring the Galea}

Galea was carefully scored approximately $1 \mathrm{~cm}$ apart along the long axis to stretch the flaps while maintaining its vascularity ( - Fig. 1B). Carefully placed incisions ensured the preservation of the subdermal vascular plexus, thus increasing flap viability. Scoring the galea reduced tension along the flap edges. ${ }^{9}$ Layered closure of the defect, minimum tension over flap edges, eversion of the wound, and fine suturing was necessary for better final results.

\section{Results}

All patients achieved adequate soft-tissue coverage over their forehead defects. Flaps in 6 out of 12 patients (50\%) were fully viable and healed uneventfully with no complications.

Fig. 1 (A) Triple-plane dissection, in subcutaneous, subgaleal, and subperiosteal planes, enables en bloc tissue advancement for covering large forehead defects without tension to flap margins. (B) Scoring of the galea perpendicular to the long axis of the wound easily allows tissue advancement toward the forehead defect. 
One patient (8\%) had superficial necrosis of the dermoepidermal layer on one side of the flap, and it healed without any further complications. One patient (8\%) had deep marginal necrosis for approximately $1 \mathrm{~cm}$ along the margins over the forehead and scalp. It healed with the formation of a depressed stretched scar. Four patients (33\%) had mild venous stasis near the tip of the flap during the initial weeks but ultimately recovered well as venous stasis resolved by itself. No infection or other problems were associated with these flaps postoperatively. Alopecia was absent in seven out of twelve patients (58\%), minimal in three patients (25\%), mild along the margins in one patient (8\%), and apparent along a $1 \mathrm{~cm}$ width on both sides of the final scar in one patient (8\%). Patient-reported outcomes questionnaire measured patient satisfaction 6 months postoperatively. It was tabulated on a visual analogue scale from 1 to 10 , with 1 being the worst and 10 being the best imaginable outcome. Satisfaction scores ranged between 3 and 9, with a mean score of 7 out of 10 ( - Table 1 ).

\section{Sample Case Reports}

Three patient histories are presented in brief to illustrate the reconstructive use of combined forehead and scalp flaps in large forehead defects.

\section{Case Number 3}

A 55-year-old man presented with a 7-day-old injury over his scalp and upper forehead following a road traffic accident, sutured up and treated initially in another hospital. Exploration revealed necrotic and putrefied frontalis muscle and galea aponeurosis, soft tissues, and skin (black arrows, - Fig. 2A). Radical debridement resulted in defects over two separate places, an $8 \mathrm{~cm} \times 5 \mathrm{~cm}$ defect involving the scalp and upper forehead and a second smaller defect over the forehead above the left eyebrow (black arrows, -Fig. 2B). Triple-plane dissection was performed, combined scalp and forehead flaps were raised, and the flaps rotated and advanced to cover the defect primarily (-Fig. 2C). The patient healed well with a satisfactory scar, and without alopecia or other problems (-Fig. 2D).

\section{Case Number 9}

A 65-year-old man suffered an injury over the lower-left forehead and eyebrow region following a collision between two vehicles, along with damage to the brain and both lower limbs. He did not require any neurosurgical intervention. An orthopaedic surgeon fixed his lower leg fractures simultaneously while the author performed his forehead flap reconstruction. After radical debridement, there was a $6 \mathrm{~cm} \times 4.5 \mathrm{~cm}$

Table 1 Patients' population

\begin{tabular}{|c|c|c|c|c|c|c|c|}
\hline ID & $M / F$ & Age (y) & $\begin{array}{l}\text { Cause of } \\
\text { trauma }\end{array}$ & Size of defect $\left(\mathrm{cm}^{2}\right)$ & Complications & Satisfaction VAS & Alopecia \\
\hline 1 & M & 62 & $\begin{array}{l}\text { Industrial } \\
\text { accident }\end{array}$ & $7 \times 4$ & Nil & $6 / 10$ & $\mathrm{Nil}$ \\
\hline 2 & $\mathrm{~F}$ & 52 & $\begin{array}{l}\text { Automobile } \\
\text { accident }\end{array}$ & $8 \times 3$ & Slight venous stasis & $7 / 10$ & Minimal \\
\hline 3 & $M$ & 55 & $\begin{array}{l}\text { Automobile } \\
\text { accident }\end{array}$ & $8 \times 5$ & Nil & $8 / 10$ & $\mathrm{Nil}$ \\
\hline 4 & M & 34 & $\begin{array}{l}\text { Industrial } \\
\text { accident }\end{array}$ & $8 \times 4$ & $\begin{array}{l}\text { Deep marginal } \\
\text { necrosis both side, } \\
\text { depressed scar }\end{array}$ & $3 / 10$ & $\begin{array}{l}1 \mathrm{~cm} \text { width, both } \\
\text { margins }\end{array}$ \\
\hline 5 & M & 68 & $\begin{array}{l}\text { Automobile } \\
\text { accident }\end{array}$ & $6 \times 3.5$ & Nil & $7 / 10$ & $\mathrm{Nil}$ \\
\hline 6 & $\mathrm{~F}$ & 73 & Fall from height & $6 \times 3.5$ & $\begin{array}{l}\text { Superficial necrosis } \\
\text { on one side }\end{array}$ & $6 / 10$ & $\begin{array}{l}\text { Mild, along involved } \\
\text { margin }\end{array}$ \\
\hline 7 & $\mathrm{~F}$ & 86 & Fall from height & $6 \times 4$ & Slight venous stasis & $8 / 10$ & $\mathrm{Nil}$ \\
\hline 8 & $M$ & 49 & $\begin{array}{l}\text { Industrial } \\
\text { accident }\end{array}$ & $7 \times 4$ & Slight venous stasis & $7 / 10$ & Nil \\
\hline 9 & M & 65 & $\begin{array}{l}\text { Automobile } \\
\text { accident }\end{array}$ & $6 \times 4.5$ & Nil & $9 / 10$ & Minimal \\
\hline 10 & M & 52 & $\begin{array}{l}\text { Automobile } \\
\text { accident }\end{array}$ & $8 \times 4$ & Slight venous stasis & $7 / 10$ & $\mathrm{Nil}$ \\
\hline 11 & $M$ & 45 & $\begin{array}{l}\text { Automobile } \\
\text { accident }\end{array}$ & $7 \times 3$ & Nil & $8 / 10$ & $\mathrm{Nil}$ \\
\hline 12 & $\mathrm{~F}$ & 60 & $\begin{array}{l}\text { Automobile } \\
\text { accident }\end{array}$ & $5 \times 5$ & Nil & $8 / 10$ & Minimal \\
\hline
\end{tabular}

Abbreviations: F, female; M, male; VAS, visual analogue scale. 
defect over his left forehead and eyebrow ( - Fig. 3A). Tripleplane dissection was combined with significant-sized scalp and forehead flaps. After scoring the galea and deep fascia, the flaps were rotated and advanced to cover the defect without any tension to flap edges ( $\mathbf{F}$ Fig. 3B). The resulting scar was satisfactory, and there was no alopecia due to the surgery.

\section{Case Number 12}

A 60-year-old lady presented to our clinic with a 3-month-old full-thickness injury involving all soft tissues and bone over her right forehead. An exposed, ulcerated, and infected frontal lobe of the brain was visible ( $\neg$ Fig. $4 \mathbf{A}$ ). After adequate neurosurgical management, the $5 \mathrm{~cm} \times 5 \mathrm{~cm}$ ulcer was covered primarily by a rotational flap combining forehead and

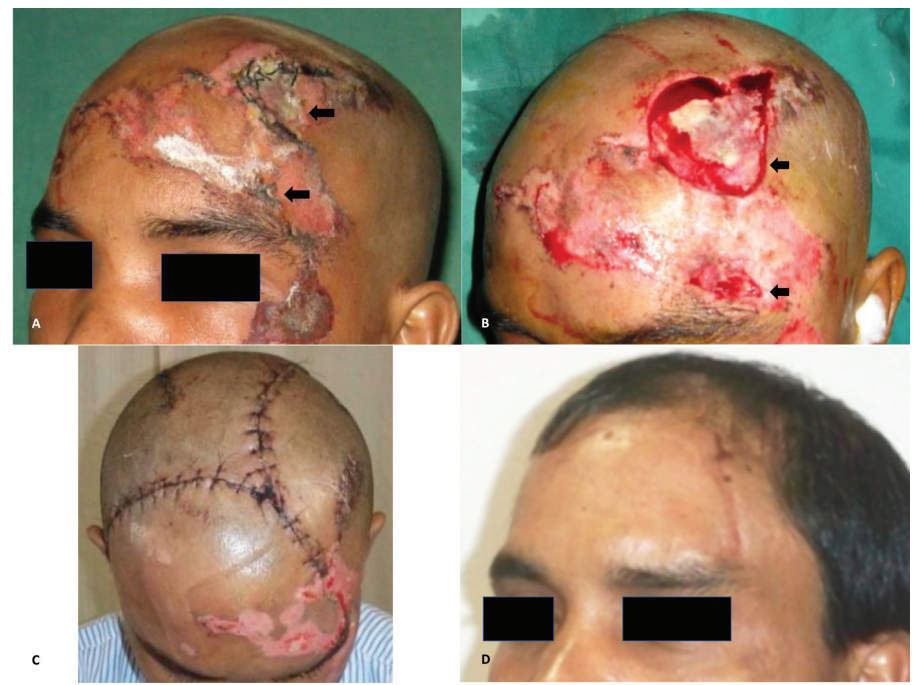

Fig. 2 (A) A 55-year-old man presented with a week-old injury with necrosed and rotten soft-tissues over the scalp and forehead (indicated with black arrows). (B) Debridement created an $8 \mathrm{~cm} \times 5 \mathrm{~cm}$ defect involving the scalp and upper forehead and a smaller defect over the left eyebrow.(C) Result of forehead reconstruction with triple-plane dissection, involving significantly-sized flaps combining forehead and scalp. (D) Long-term result with an acceptable scar and no alopecia.

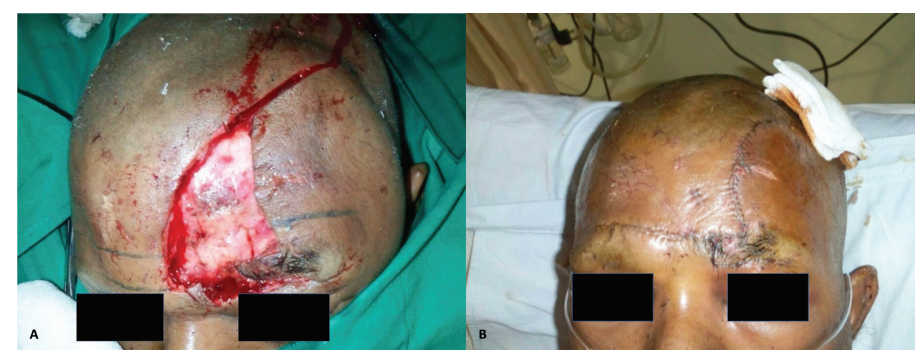

Fig. 3 (A) A 65-year-old man presented with a $6 \mathrm{~cm} \times 4.5 \mathrm{~cm}$ defect over the left side of his forehead following an automobile accident. (B) Resulting suture lines after forehead reconstruction.

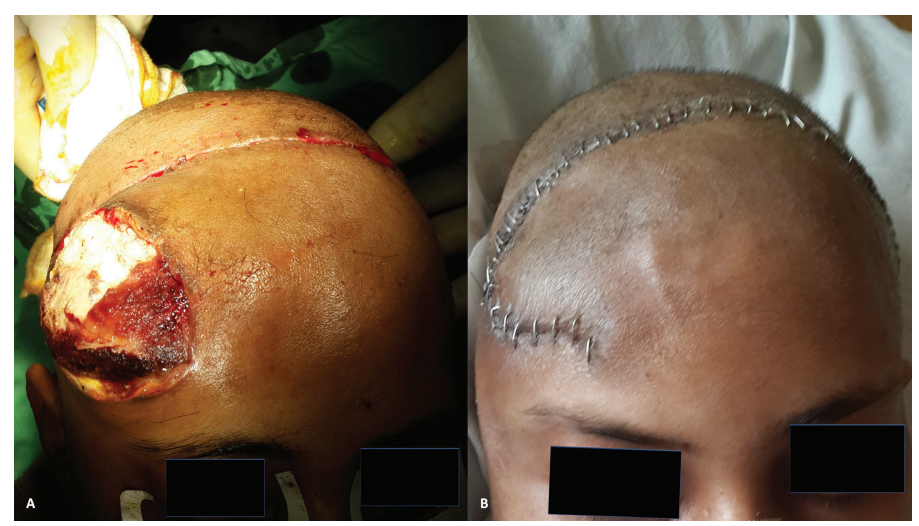

Fig. 4 (A) A 60-year-old lady presented with an old neglected $5 \mathrm{~cm} \times 5 \mathrm{~cm}$ ulcer over her right forehead with an infected exposed frontal lobe of the brain. (B) Suture lines after reconstruction with triple-plane dissection, and significant forehead and scalp tissue mobilization. 
anterior scalp and advancement of the rest of the scalp ( - Fig. 4B). The resultant scar was satisfactory without any noticeable alopecia.

\section{Discussion}

The forehead has an immense esthetic importance. It is bounded by many anatomical landmarks and has low availability of adjacent donor tissues. Achieving a satisfying esthetic reconstruction without distorting the anatomic landmarks is a challenge in plastic surgery. Primary repair of the defect is ideal but limited to sizes less than $3 \mathrm{~cm}$, and are not possible for covering large forehead defects. Even for this size, significant undermining of adjacent tissues is necessary. Chances of scar complications are higher when closure is attempted under high-tissue tension. Distortion of the eyebrows is possible when reconstruction is attempted over the defects near the eyes. ${ }^{7}$

Skin grafts are commonly used to cover different defects over the head and neck region. Full-thickness skin grafts have been widely used for scalp and forehead reconstruction. They are usually taken from the postauricular regions, medial arm, and supraclavicular fossa, which are closed primarily. However, it is difficult to obtain large grafts to cover large forehead defects by this method. Split-thickness skin grafts are easy and often utilized for covering defects if the underlying bone is not exposed. It is especially beneficial for patients unable to undergo long-duration surgeries. However, it is characterized by significant postoperative pain and graft contraction, with poor color and contour match in the long-term, and low levels of patient acceptance and satisfaction. ${ }^{6,10}$

Dermal substitutes include allogenic acellular dermal matrix and dermal regenerative template. They may be used for dermal reconstruction and followed by split-thickness skin grafting after a few weeks. For patients with large defects, these biomaterials provide an alternative to microvascular free-tissue transfers, which can be performed quickly and allow patients to go home early. ${ }^{11}$ Still, they usually require many additional procedures, like multiple sessions of negative pressure wound therapy. They are prone to loss of matrix in infections, are costly, require second skin-grafting surgery, and the esthetic outcome is hampered by the limitations of the overlying split-skin graft (as detailed above).

Microvascular free-tissue transfers are often recommended in defects over scalp and forehead exceeding $50 \mathrm{~cm}^{2}$. They are increasingly performed in large $\left(>20 \mathrm{~cm}^{2}\right)$ forehead defects as well. They are valuable in trauma, radiation, compromised local and regional tissues, and failed local flaps. This procedure requires long operating hours, specialized instrumentation, and intensive care unit (ICU) back-up whenever necessary. However, there is a lingering problem of inadequate color matching that lowers patient satisfaction in the long term. ${ }^{12}$
This article aims to demonstrate the advantage of a significant combined forehead and scalp flap for reconstructing large defects over the forehead. An ideal donor area for covering a forehead defect should ideally have these following attributes ${ }^{13}$ :

- Thickness of the flap matching that of the normal forehead

- Excellent vascularity, extending up to the tip of flaps

- Good color match

- Minimum scar and pigmentation problems

- No hair loss or alopecia over the scalp

- Proper contouring and draping over different convexities of the scalp

Only a locoregional flap comprising forehead and scalp tissues can fulfill all these attributes. With an increasing emphasis on the esthetic outcome of our patients, utilizing forehead tissues is essential. Any distant flap comprising tissues from other parts of the body will look and feel different. Tissue expansion of adjacent areas provides similar tissues. Still, it is hampered by requirements for multiple surgeries, associated pain, social isolation of the patient due to odd looks, need for regular follow-up for months together, chances of failure from infection and extrusion, and additional cost of expanders. ${ }^{14}$ Patient acceptance of expanders in this part of the world is low. For example, we counseled all our 12 patients about the use of expanders but none agreed.

Transposition flaps are commonly used in different areas of head and neck reconstruction but are not popular for forehead reconstruction. Examples of transposition flaps include rhomboid flaps like the Limberg (trapezoidal 60-degree), Dufourmental (trapezoidal, acute angle), and Webster (30-degree flap with M-plasty). The orientation of these flaps often violates RSTL. Resultant scars may become stretched, more visible, or even hypertrophic over the long term. Maintaining eyebrow and hairline positions becomes difficult when reconstructing large forehead defects with this method. ${ }^{15}$

Rotation and advancement flaps are amongst the most commonly used flaps for forehead reconstruction. These flaps are inspired by and developed from scalp reconstruction techniques originally described by Orticochea. ${ }^{8}$ Orticochea used a three-flap design initially, with two flaps being for advancement and the third flap for rotation. The use of adjacent tissues which are similar in appearance, with good contour and good color match, and with incision lines being well-camouflaged within RSTL, is among the significant advantages of these flaps. Different derivative methods have been described after Orticochea, including O-T flaps, A-T flaps, V-Y advancement flaps, and O-Z flaps. Disadvantages of these flaps include the moderate-to-large amount of tissue undermining that is required to mobilize these flaps, a necessity for multiple and large incisions, with resultant longer scars and chances of alopecia in hair-bearing areas. This technique appears to be better suited for older 
patients with more laxity of their tissues compared with young patients with tight skin and a low-lying hairline.,2,3,16,17

\section{Conclusion}

A significant-sized rotation-advancement flap, combining forehead and scalp, is an effective solution for covering large forehead defects. More tissue is recruited by triple-plane dissection and by scoring the galea, which allows it to cover large defects while maintaining adequate flap vascularity. It has a good color and contour match, with low incidences of alopecia, and satisfactory scar formation. It has high levels of patient acceptance and satisfaction and is more esthetically pleasing.

\section{Disclosure}

S.S. is an unpaid consultant with Dr Reddy's Laboratories, India.

\section{Conflict of Interest}

None declared.

\section{Acknowledgments}

The author acknowledges the help he received in collecting some of the patients' data from Prof. Robindro Nath Bhattacharya, Dr. Binod Kumar Singhania, and Dr. Subhashis Das.

\section{References}

1 Sokoya M, Inman J, Ducic Y. Scalp and forehead reconstruction. Semin Plast Surg 2018;32(2):90-94

2 Boustany A, Ghareeb P, McClellan WT. Forehead reconstruction using a modified dual-plane A to T flap. Can J Plast Surg 2012;20(4):251-254

3 Ransom ER, Jacono AA. Double-opposing rotationadvancement flaps for closure of forehead defects. Arch Facial Plast Surg 2012;14(5):342-345
4 Mathes SJ, Nahai F, Clinical Applications for Muscle and Musculocutaneous Flaps. St Louis, MO: CV Mosby; 1982

5 Shumrick KA, Smith TL. The anatomic basis for the design of forehead flaps in nasal reconstruction. Arch Otolaryngol Head Neck Surg 1992;118(4):373-379

6 Seitz IA, Gottlieb LJ. Reconstruction of scalp and forehead defects. Clin Plast Surg 2009;36(3):355-377

7 Quatrano NA, Dawli TB, Park AJ, Samie FH. Simplifying forehead reconstruction: a review of more than 200 cases. Facial Plast Surg 2016;32(3):309-314

8 Orticochea $M$. New three-flap reconstruction technique. Br J Plast Surg 1971;24(2):184-188

9 Newman MI, Hanasono MM, Disa JJ, Cordeiro PG, Mehrara BJ. Scalp reconstruction: a 15-year experience. Ann Plast Surg 2004;52(5):501-506, discussion 506

10 Pitkanen JM, Al-Qattan MM, Russel NA. Immediate coverage of exposed, denuded cranial bone with split-thickness skin grafts. Ann Plast Surg 2000;45(2):118-121

11 Richardson MA, Lange JP, Jordan JR. Reconstruction of full-thickness scalp defects using a dermal regeneration template. JAMA Facial Plast Surg 2016;18(1):62-67

12 Hussussian CJ, Reece GP. Microsurgical scalp reconstruction in the patient with cancer. Plast Reconstr Surg 2002; 109(6):1828-1834

13 Pennington DG, Stern HS, Lee KK. Free-flap reconstruction of large defects of the scalp and calvarium. Plast Reconstr Surg 1989;83(4):655-661

14 O'Reilly AG, Schmitt WR, Roenigk RK, Moore EJ, Price DL. Closure of scalp and forehead defects using external tissue expander. Arch Facial Plast Surg 2012;14(6):419-422

15 Pribaz JJ, Caterson EJ. Scalp and forehead reconstruction. In Rodriguez ED, Losee JE, Neligan PC, eds. Plastic Surgery. Vol. 3: Craniofacial, Head and Neck Surgery and Pediatric Plastic Surgery (Fourth Edition). 2018:92--125.e3

16 Moulton-Barrett R, Vanderschelden B. Double opposing unilobar rotation flaps in the reconstruction of moderate-to-large defects of the scalp. J Craniofac Surg 2015;26(6):e523-e525

17 Rocha LS, Paiva GR, de Oliveira LC, Filho JV, Santos ID, Andrews JM. Frontal reconstruction with frontal musculocutaneous V-Y island flap. Plast Reconstr Surg 2007;120(3): 631-637 